\title{
INVESTIGATION OF SELF-ASSEMBLED NANOFIBERS USING ATOMIC FORCE MICROSCOPY
}

\author{
M. E. Salmon ${ }^{*}$, P.E. Russell* and E.B. Troughton Jr.* \\ * - AIF - North Carolina State University, Campus Box 7531, Raleigh, NC 27695, USA \\ ** - Thomas Lord Research Center, Lord Coporation, Box 8012, Cary, NC 27512, USA
}

Self-assembled structures are of increasing interest today due to the rapid progression of micro- and nano- scale engineering applications. In recent years much attention has been placed on understanding the formation and properties of monomolecular thin films, also known as selfassembled monolayers (SAMS), for use as corrosion inhibitors, lubricants, and adhesion promoters $^{1,2}$. Much of the advancement in this field has come from the unprecedented resolution of scanned probe microscopy, the scanning tunneling microscope (STM) and the atomic force microscope (AFM), invented in the mid to late 1980's.

In this study we use TappingMode ${ }^{\mathrm{TM}}$ AFM to investigate the changes in the surface topography, over time, of evaporated aluminum on glass subjected to a $0.1 \mathrm{wt} \%$ methylphosphonic acid (MPA)/ethanol solution at ambient conditions, ex-situ. The aluminum surfaces were prepared by evaporating $200 \mathrm{~nm}$ of Aluminum onto cleaned microscope slides. As deposited, the Aluminum surface exhibits a grain size distribution of approximately $20 \mathrm{~nm}$ to $200 \mathrm{~nm}$ with an RMS roughness of $\sim 4 \mathrm{~nm}$ over a $5 \mathrm{um}$ x $5 \mathrm{um}$ region (Figure 1a). Ten samples were added to $30 \mathrm{~mL}$ of the MPA solution and were then removed one at a time over the course of 177 days. Once removed each sample was rinsed with ethanol, blown dry with dry nitrogen, and imaged with AFM immediately.

Figures $1 \mathrm{~b}-1 \mathrm{~h}$ are $5 \mathrm{um} \times 5 \mathrm{um}$ TappingMode ${ }^{\mathrm{TM}}$ AFM height images showing the time evolved growth of nano-fibrous structures on the aluminum surface. It appears that growth of the fibers begins within a day of exposure to the solution (arrow in Figure 1b). After 28 days (Figure 1e) the initial Aluminum microstructure is hardly visible beneath the intersecting growth of the fibers. By 177 days, the fibers appear to form a non-woven fabric like structure where individual fibers branch, intersect, and overlap one another forming a continuous network. Figure 2 shows a $1 \mathrm{um} x$ $1 \mathrm{um}$ phase image of this interconnected structure. The sizes of the fibers change over time, but are typically less than $150 \mathrm{~nm}$ in width and are sometimes more than a micron in length after 25 days. The RMS roughness of the surfaces increases over time from $\sim 4 \mathrm{~nm}$ initially to over $50 \mathrm{~nm}$ after 177 days. Figure $1 \mathrm{i}$ shows that fibers are also found on the backside glass, but are far fewer in number and size than that of the Aluminum side of the 177 day sample.

In conclusion we have shown that novel fibrous structures are formed on the surface of Aluminum by immersion into a $.01 \mathrm{wt} \% \mathrm{MPA} /$ Ethanol solution over time. The fibers grow, completely covering the surface after 177 days. Fibers are also found on the backside glass of the same samples, but much less in number and size than the Al surface. Currently, new techniques involving TEM and AFM are being developed to help determine the structure and properties of the individual fibers as well as the whole fabric.

[1] - P.E. Laibinis, et al., Science 245 (1989) 845.

[2] - A. Ulman, An Introduction to Ultrathin Films, Academic Press, San Diego, USA (1991). 

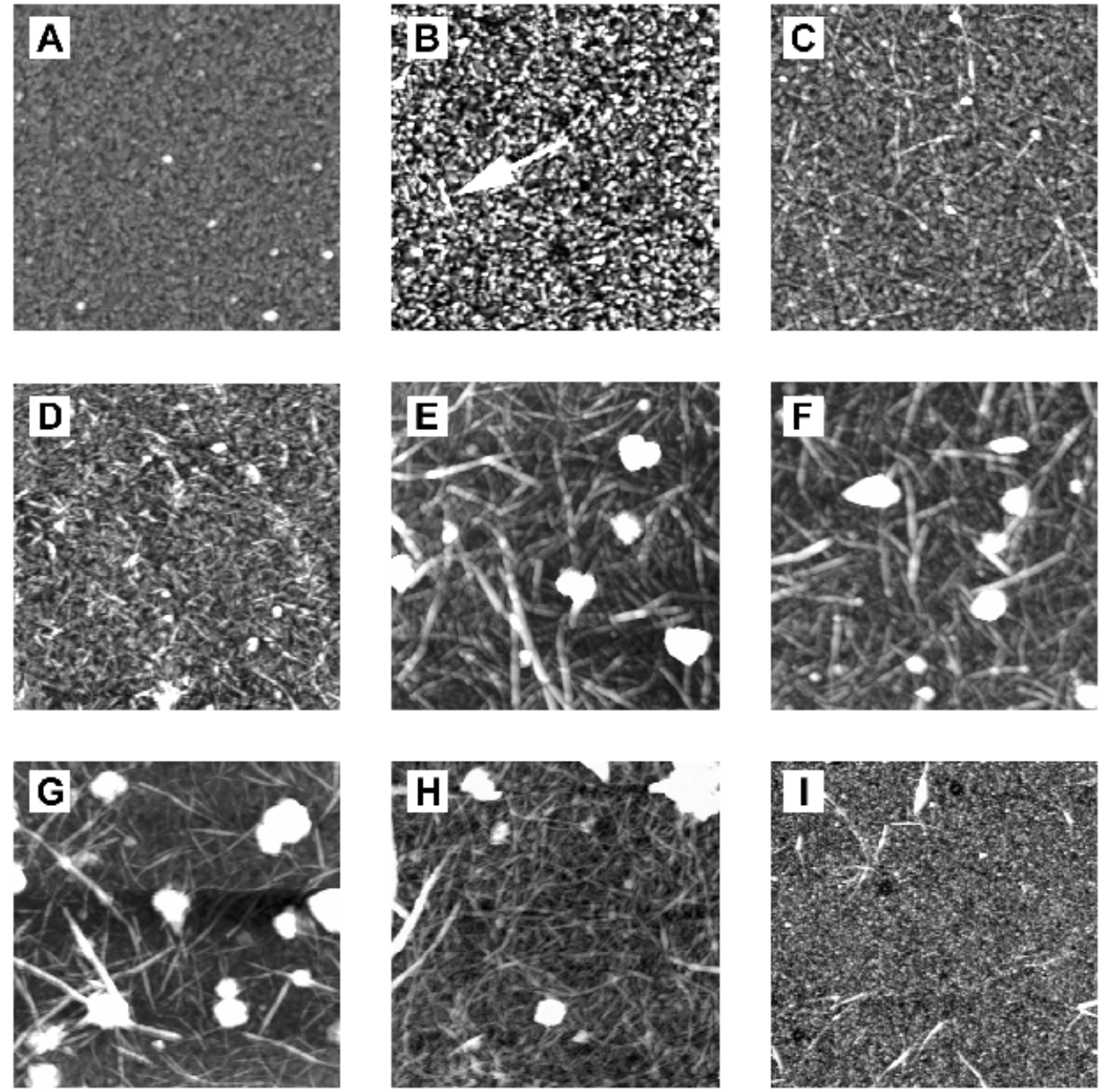

Figure 1. (A-H) are 5 um x 5 um AFM TappingMode ${ }^{\mathrm{TM}}$ height images showing the time evolution $(0,1,2,8,28,35,84,177$ days respectively) of the surface of Aluminum as it is subjected to a 0.1 wt\% methylphosphonic acid/Ethanol Solution. (I) 5 um x 5 um of backside glass 177 days immersion.

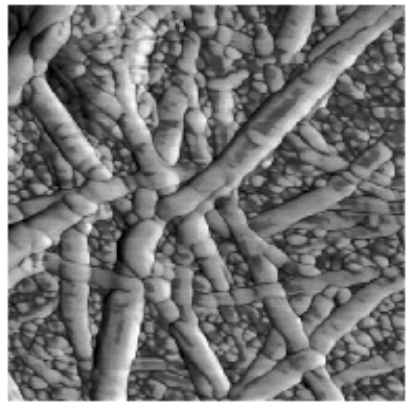

Figure 2. 1 um x 1 um TappingMode ${ }^{\mathrm{TM}}$ AFM phase image of an area within Figure $1 \mathrm{~g}$. showing detail of how the individual fibers overlap, branch, and intersect one another. 